\title{
AN ATTEMPT AT REVERSIBILITY AND INCREASE OF THE VIRULENCE OF AXENIC STRAINS OF Entamoeba histolytica
}

\author{
Maria Aparecida GOMES (1), Adriana Oliveira COSTA (1), Washington Luiz TAFURI (2) \& Edward Félix SILVA (1)
}

\section{SUMMARY}

In this study we have tried to verify whether the interaction "in vitro"with bacteria or small pieces of normal hamster liver would modify the pathogenic behavior of axenic strains of $E$. histolytica: avirulent ones (ICB-32 and ICB-RPS), of attenuated virulence (ICB-CSP and HM1) and of mean virulence (ICB-462). Every attempt to render virulent, recover or increase the virulence of axenic strains of E. histolytica has failed.

KEYWORDS: Entamoeba histolytica; Axenic cultures; Ameba-bacterium interaction; Virulence.

\section{INTRODUCTION}

Entamoeba histolytica is dispersed widely and about $10 \%$ of the world's population carry the parasite, although a much smaller percentage suffer disease. Clinical signs of infection vary in different parts of the world. These variations seem to be related to factors such as the parasites, the host and the environment. Several studies ${ }^{2.15}$, have investigated the interplay between these factors, but conditions governing the change from an intestinal commensal organism to an aggressive, tissue invader have received little attention.

"In vitro" axenic cultivation of amebae ${ }^{10,12}$ has enhanced knowledge about the virulence of parasites and has permitted studies on the pathogenicity of trophozoites grown in the absence of microorganisms with which they are usually associated within the human body. The degree of virulence of trophozoites of Entamoeba histolytica, isolated from different patients, can be assessed experimentally on the basis of three criteria: the ability to form hepatic abscesses in golden hamsters ${ }^{11,16}$; cytopathic and cytotoxic effects in cultured mammalian cells ${ }^{3.19,23}$; and erythrophagocytosis $\mathrm{s}^{20,27}$.

Assessment of the virulence of amebae is handicapped by the fact that prolonged culture in an axenic medium can diminish virulence ${ }^{2,16,22}$, but virulence can be revived by "in vivo"passage of a strain in the liver of golden hamsters ${ }^{8,11,14}$. Virulence of a strain can also be enhanced by adding pieces of normal hamster liver to axenic cultures ${ }^{1}$, or by incorporating bacteria ${ }^{4,5,28}$.

In this study, we have tried to check whether the avirulent strains of $E$. histolytica (ICB-32 and ICB-RPS) would undergo any change regarding their pathogenicity, when associated with bacteria, since there are very few experimental data about avirulent axenic strains in literature. We have further tried to

(I) Department of Parasitology, Institute of Biological Sciences, Federal University of Minas Gerais, Belo Horizonte, MG, Brazil.

(2) Department of Biological Sciences, Institute of Biological and Exact Sciences, Federal University of Ouro Preto, Ouro Preto, MG, Brazil. Address for correspondence: Dr. Edward Félix Silva, Departamentode Parasitologia, Instituto de Ciências Biológicas, Universidade Federal de Minas Gerais. Av. Antônio Carlos, 6627, CEP 31270-010, Belo Horizonte, Minas Gerais, Brasil. 
GOMES, M.A.; COSTA, A.O.; TAFURI, W.L. \& SILVA, E.F. - An attempt at reversibility and increase of the virulence of axenic strains of Entamoeba histolytica. Rev. Inst. Med. trop. S. Paulo, 35 (6):503-508, 1993.

verify if the loss of virulence of the strains kept in axenic culture (HMI and ICB-CSP) is a reversible phenomenon and investigate a possible modification in the pathogenic behavior of a mean virulent strain (ICB-462), following association with bacteria and incubation with small pieces of normal hamster liver.

\section{MATERIAL AND METHODS}

\section{STRAINS OF E. histolytica USED:}

- HMI-IMSS* : Isolated from a patient with symptoms of amebiasis by DE LA TORRE ${ }^{9}$ in Mexico. DIAMOND ${ }^{11}$ used it under axenic condition in 1971. It was considered virulent.

- ICB-CSP* : Isolated in 1969 from a patient with symptoms of acute amebic dysentery and regarded as highly virulent ${ }^{8}$. This strain has been cultured axenically since 1981 .

- After prolonged axenic cultivation these strains are how considered to be attenuated, and do not produce liver abscesses when inoculated into hamsters.

- ICB-462: Isolated in 1980 directly from cysts in feces of a asymptomatic carrier. It was used under axenic conditions in 1981 and deemed to be of moderate virulence.

- ICB-32: Isolated in 1979 directly from cysts of a asymptomatic carrier, it was submitted to axenic conditions in 1981 and was considered avirulent.

- ICB-RPS: Isolated in 1989 directly from cysts of a asymptomatic carrier, is avirulent and has been cultivated axenically since 1990 .

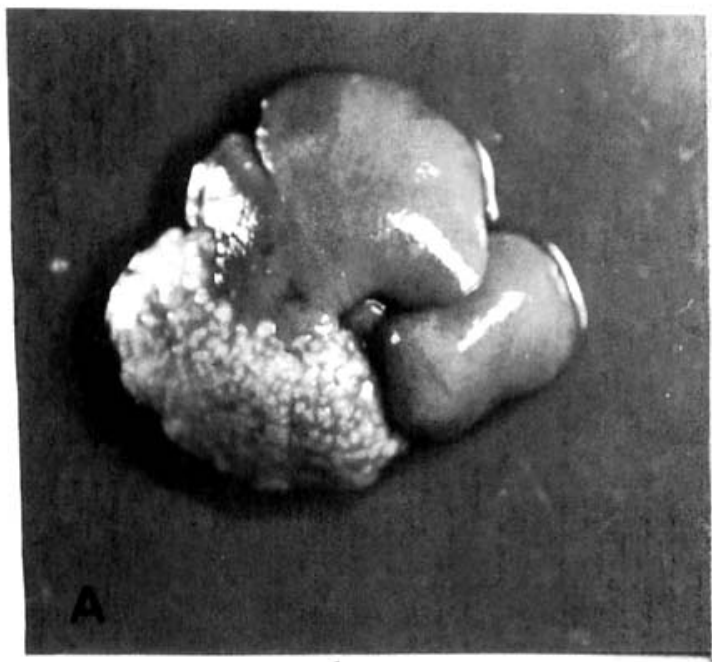

All the strains of $E$. histolytica that were utilized, excepting HM1, were isolated in Belo Horizonte, MG, Brazil and submitted to axenic conditions in TPS-1 or TYI-S-33 medium by SILVA et al. ${ }^{24}$.

\section{STRAINS OF BACTERIA:}

- Escherichia coli O55 and O115, living were kindly provided by Dr. Mirelman, Weizmann Institute of Sciences, Israel. These bacteria have been described ${ }^{5,17}$ as being able to increase the virulence of amebae.

- E. coli from the original flora of ICB-CSP strain.

- E. coli $\mathrm{O} 55$ and 0115 , killed by lethal radiation with 500.000 rads from a source of cobalt.

\section{Interaction between ameba and bacteria}

In each experiment, the amebae were exposed to a single strain of living bacteria, at intervals ranging from 1 to 72 hours in TPS-1 or TYI-S-33 medium at $37^{\circ} \mathrm{C}$. After the time of association had elapsed, the amebae were washed in a $0.85 \%$ saline solution, to remove bacteria. The viability of trophozoites was checked through $0.125 \%$ of eosin and counted in Neubauer's chamber, in order to ascertain the size of the inoculum. Approximately $1 \times 10^{8}$ bacteria, lethaly irradiated by a cobalt source were also associated with amebae for 10 days, the medium containing the bacteria being changed every 48 hours.

\section{Incubation with liver snips}

Small pieces of approximately $1 \mathrm{~mm}^{3}$ of normal hamster liver, were added to twenty-four hour cultures

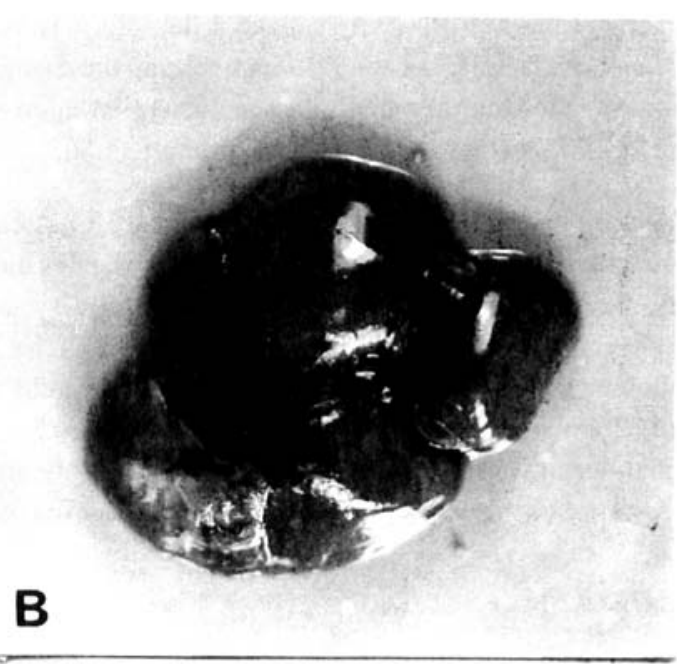

Fig. 1 - Liver of hamster inoculated with A) $1.0 \times 10^{6}$ trophozoites of the axenic strain ICB- 462 of E. histolytica and B) associated 24 hours with $E$. coll 055 
GOMES, M.A.; COSTA, A.O.; TAFURI, W.L. \& SILVA, E.F. - An attempt at reversibility and increase of the vinulence of axenic strains of Entamoeba histolytica. Rev. Inst. Med. trop. S. Paulo, 35 (6):503-508, 1993.

of amebae and incubated at $37^{\circ} \mathrm{C}$ for 48 hours. Following the period of incubation, the amebae were washed in a saline solution and the inoculum was determined by counting the viable trophozoites in Neubauer's chamber.

\section{Inoculation in Hantsters}

Both male and female hamsters, one month old, were intrahepatically inoculated under sterile conditions. Six days after the inoculation, the animals were sacrificed and their livers examined macroscopically and microscopically to detect parasites. Liver fragments were fixed in $10 \%$ buffered ( $\mathrm{pH} 7.2$ ) formalin, embedded in paraffin, sectioned $(5 \mu \mathrm{m})$ and stained with hematoxylin-eosin (H.E.). Other bits of liver were inoculated in a culture medium containing Crithidia fasciculata as an attempt to reisolate the ameba.

\section{RESULTS}

The virulent though attenuated strains of $E$. histolytica (ICB-CSP and $\mathrm{HMl}$ ) and the avirulent ones (ICB32 and ICB-RPS), kept in axenic cultivation, produced no abscess when they were inoculated into the liver of hamsters. These strains were not reisolated in culture medium containing $\mathrm{C}$. fasciculata and under histopathologic examination no amebae were found. ICB-462 strain (mean virulence) caused abscesses in $25 \%$ of the hamsters inoculated (Fig. IA). The results were positive not only with regard to the isolated cultures starting from these animals, but also concerning the findings of the parasite in the slides stained with H.E. (Table 1).

The bacteria E. coli $055, \mathrm{O} 115$ as well as $E$. coli from the original flora of the strain of E. histolytica ICBCSP were inoculated into the liver of hamsters. They caused lesions in all the animals inoculated $(100 \%)$.

The strain of E. histolytica ICB-CSP was associated with $E$. coli OSS for a period ranging from 1 to 48 hours. No experiment whatever showed the formation of amebic hepatic abscesses (Table 2). Only the typical bacterial lesion was found in the liver. All attempts at reisolation by using culture tecniques failed. From a histopathological viewpoint, it was observed a focal productive purulent hepatitis (formation of abscesses bearing a central area, almost exclusively constituted of both intact and degenerate granulocytes neutrophils, enveloped by a characteristic pyogenic membrane and the beginning of formation of a conjunctive capsule). A diffuse productive chronic inflammation with giant cell type, showing intense conjunctive neoformation together with inflitrates of mononuclear cells (granulocytes neutrophils, lymphocytes and macrophages) were evinced as well as fatty albuminous degeneration of hepatocytes. The research for amebae was negative. This strain was also associated with bacteria E. coli O1 15 and $E$. coli from its original flora, undergoing a treatment and showing results resembling those in Table 2 , in order to be associated with $E$. coli 055 .

Similar experiments concerning the strains of $E$. histolytica ICB-32, ICB-RPS and HM1 were carried out, varying only with reference to the size of the inoculum of the trophozoites. The same results as found for ICBCSP strain were detected.

The results of the association of ICB-462 strain with $E$. coli $\mathrm{O} 115$ are shown in Table 3. Microscopically, we can observe several amebic abscesses at different stages: some with coliquative necrosis in the center, enveloped by several granulocytes neutrophilis and mononuclear cells among a large number of still intact amcbae; others without central coliquative necrosis, but with many granulocytes already undergoing degenerative phenomena. Isolated nest of amebae intact or in

TABLE 1

Intrahepatic inoculation of Ilamsters with different strains of E. histolvtica from axenic culture.

\begin{tabular}{lcccc}
\hline STRAIN & INOCULUM & $\begin{array}{c}\text { AMEBIC HEPATIC } \\
\text { ABSCESSES }\end{array}$ & $\begin{array}{c}\text { ISOLATION* } \\
\text { DEREE OF INFECTION } \\
\text { (I to V) }\end{array}$ \\
\hline HM1-IMSS & $9.5 \times 10^{6}$ & $0 / 16$ & $0 / 16$ & nd \\
ICB-CSP & $2.0 \times 10^{6}$ & $0 / 16$ & $0 / 16$ & nd \\
ICB-462 & $3.5 \times 10^{6}$ & $4 / 16$ & $4 / 16$ & II, III and V \\
ICB-RPS & $5.0 \times 10^{6}$ & $0 / 16$ & $0 / 16$ & nd \\
ICB-32 & $2.0 \times 10^{6}$ & $0 / 16$ & $0 / 16$ & nd \\
\hline
\end{tabular}

* Fragments of liver were inoculated in culture medium containing Crithidia fasciculata.

nd $=$ lesion was not detected. 
GOMES, M.A.; COSTA, A.O.; TAFURI, W.L. \& SILVA, E.F. - An attempt at reversibility and increase of the virulence of axenic strains of Entamoeba histolyica. Rev. Inst. Med. trop. S. Paulo, 35 (6):503-508, 1993.

TABI.E 2

Intrahepatic inoculation of the strain of E. histolytica ICB-CSP a fler association with living $E$. coli 055 by various time intervals.

\begin{tabular}{cccc}
\hline $\begin{array}{c}\text { ASSOCIATION TIME } \\
\text { (hours) }\end{array}$ & $\begin{array}{c}\text { FINAL RATIO } \\
\text { BACTERIA-TROPHOZOITES }\end{array}$ & INOCULUM & $\begin{array}{c}\text { AMEBIC HEPATIC } \\
\text { ABSCESSES* }\end{array}$ \\
\hline 1 & $1,500: 1$ & $3.0 \times 10^{6}$ & $0 / 8$ \\
6 & $1,000: 1$ & $2.0 \times 10^{6}$ & $0 / 8$ \\
12 & $2,000: 1$ & $1.5 \times 10^{6}$ & $0 / 12$ \\
16 & $2,500: 1$ & $1.7 \times 10^{6}$ & $0 / 9$ \\
24 & $6,000: 1$ & $1.0 \times 10^{6}$ & $0 / 10$ \\
48 & $10,000: 1$ & $4.5 \times 10^{5}$ & $0 / 6$ \\
\hline
\end{tabular}

* The hamsters were sacrificed 6 days after inoculation.

process of dissolution, with very little reaction around them, were also observed. Amebae were found only in the animals with amebic hepatic abscess. The experiments for reisolation only were positive when there were abscesses. ICB-462 strain was associated with bacteria E. coli $\mathrm{O} 55$ and E. coli from original flora of ICB-CSP strain. It showed no results different from the ones achieved when it associated with $E$. coli 0115 .

The strains of amebae associated with irradiated bacteria and the strains incubated with liver of normal hamsters behaved as the axenic strains showed in Table 1 . They did not produce any lesions or abscesses in the hamsters inoculated, neither were they reisolated in cultures.

\section{DISCUSSION}

Several investigations have been carried out aiming at the understanding of the factors that determine the virulence of $E$. histolytica. Factors such as associated bacterial flora, cholesterol, food and passages through the liver of hamsters living and "in vitro"have shown to modify the virulence of E. histolytica. In this study, we have investigated two of these factors: bacterium associated with ameba and the treatment with small picces of normal hamsters liver "in vitro".

It is known that the passage through the liver of hamsters increases the virulence of the amebae ${ }^{8,14,18}$. However, when its virulence is lost, following successive feedings to axenic cultures, one is no longer able to infect experimental animals with the attenuated strains. Therefore, it does not seem possible to restore the lost virulence, at least by this procedure. The incubation of E. histolytica with fragments of liver of normal hamster has been found to increase its virulence ${ }^{1}$. For the purpose of verifying whether this treatment would be able either to restore or to increase the virulence of strains of $E$. histolytica that we have used, the trophozoites were incubated with liver of normal hamsters. In no experiment did we manage either to change or to restore the virulence of the strains of $E$. histolytica. These results are in accordance with the observations of BOHL et al' concerning the reversibility of the virulence. Nevertheless, they differ in relation to the increase of the virulence, since ICB -462 strain has not changed its behavior following the incubation with liver of normal hamsters. The inoculation of this same strain into the liver of hamsters and its reisolation and subsequent inoculation, increase its virulence, as it has been proved by the greater number of animals with anebic hepatic abscess (unpublished data).

Irradiated bacteria were able to modify the zymodeme and the virulence of strains of $E$. histolytica ${ }^{17}$. In our experiments, however, the amebae associated with irradiated bacteria have not changed their pathogenic behavior.

Several investigators have shown that the virulence of $E$. histolytica increases after association with living bacteria ${ }^{4,5,21,28}$. Little do we know, however, about the ability of these bacteria to change a commensal ameba into a pathogenic one. This is due to the difficulty in submitting the avirulent strains to axenic conditions.

Axenic strains of $E$. histolytica that lost their pathogenic potential, because they had long been kept in a cultivation medium, were able to restore their virulence when associated with living bacteria $a^{4,5,28}$. Nevertheless, the same did not happen when we associated ICB-CSP and IIM1 strains with bacteria, inclusively E. coli $\mathrm{O} 55$ and 0115 . These were associated with some strains of E. histolytica, leading to an increase of their virulence ${ }^{4,5}$. Later experiments ${ }^{5}$ have established that the period of association ameba-bacterium is not a significant factor in so far as the increase of virulence is concerned. In spite of this, we 
have carried out this association for periods ranging from 1 to 72 hours. So, we went beyond what was observed by WITTNER \& ROSEMBAUN ${ }^{28}$, who found it necessary a minimal period from 6 to 12 hours for association with living bacteria.

The approximate relation between bacterium and ameba suggested, as an important factor to alter the virulence of amebae, was $1,000 / 1^{4}$. In this work, we have utilized relations varying from $1,000 / 1$ to $100,000 / 1$. Nevertheless, even with such high relations, HMI and ICB-CSP strains were not able to restore their virulence. This is in agreement with the findings of PIIILLIPS ${ }^{22}$, who tried to restore the virulence of NIII-200 strain by associating it with several types of bacteria, without any success. He concluded that the loss of virulence was an irreversible phenomenon.

Besides the bacteria E. coli $\mathrm{O} 55$ and $\mathrm{O} 115$, we have used $E$. coli from the original flora of ICB-CSP strain, which did not revert the virulence of HMI and ICB-CSP strains either. The latter, when isolated, was submitted to monoaxenic conditions, with this same bacterium and it produced abscess in the liver of hamsters and in albino rats. Owing to these results, we are trying to submit the recently isolated strains of $E$. histolytica to axenic conditions, so that new associations with bacteria may tell if the reversibility of virulence depends on keeping the amebae in axenic cultivation for a long period or on keeping the bacteria in storage medium for long as well. At present, we are associating ICB-CSP strain with the flora from a strain of ameba recently isolated from a symptomatic patient and which showed to be pathogenic in the liver of hamsters. The association lasted 24 hours and the inoculum was of $4.5 \times 10^{6}$ trophozoites. No inoculated hamster presented amebic hepatic abscess.
With regard to the increase of virulence, no significant difference (Fisher's exact test) was observed before and after the association of ICB-462 strain with bacteria. This can be observed by comparison with Tables 3 and 1. $\Lambda \mathrm{s}$ for the qualitative aspect of the lesions, the association with bacteria does not seem to have contributed to increase the degree of infecction of this strain (Fig. $1 \mathrm{~A}$ and $1 \mathrm{~B})$.

The avirulent strains (ICB-32 and ICB-RPS) after association with bacteria, did not modify their original features, remaining avirulent. Considering that ICBRPS strain was recently isolated as well as submitted to axenic conditions, and that this is one of the few studies carried out with avirulent strains in axenic cultivation, we can suppose that the conversion of a commensal ameba into a pathogenic one is not very likely to occur. In spite of this, it is necessary the inclusion of a larger number of a virulent axenic strains, so that we may agree with BRUMPT'S theory ${ }^{6}$, reinforced by GRAHAN CLARK et al. ${ }^{13}$. They admit that $E$. histolytica comprises two distinct species: a pathogenic and a non pathogenic one. The fact is that the association amebabacterium has several obscure points which remain speculative, concerning how the bacteria interfere with the virulence of amebae.

\section{RESUMO}

Tentativa de reversibilidade e aumento de virulência de Cepas Axênicas de Entamoeba histolytica.

Neste trabalho procuramos verificar se a interação "in vitro"com bactćrias e fragmentos de figado de hamster normal, modificaria o comportamento patogênico de cepas axênicas de E. histolytica avirulentas (ICB-32 e ICBRPS); virulentas, porém atenuadas (ICB-CSP e IIMI) e de

TABLE 3

Intrahepatic inoculation of the strain of E. hystolytica ICB- 462 after association with living $E$. Coli 0115 by various time intervals.

\begin{tabular}{cccc}
$\begin{array}{c}\text { ASSOCIATION TIME } \\
\text { (hours) }\end{array}$ & $\begin{array}{c}\text { FINAL RATIO } \\
\text { BACTTRIA-TROPIOZOITES }\end{array}$ & $\begin{array}{c}\text { AMIBBIC IIIPATIC } \\
\text { ABSCESSES* }\end{array}$ & $\begin{array}{c}\text { INFECTION DEGREE } \\
\text { (I to V) }\end{array}$ \\
\hline 1 & $1,500: 1$ & $4 / 15$ & II-IV \\
6 & $100,000: 1$ & $5 / 16$ & II-IV \\
12 & $100,000: 1$ & $4 / 16$ & III-IV \\
16 & $5,000: 1$ & $5 / 15$ & I-IV \\
24 & $5,000: 1$ & $5 / 14$ & II-V \\
48 & $10,000: 1$ & $3 / 11$ & II-IV \\
72 & $20,000: 1$ & $3 / 10$ & II-IV \\
\hline
\end{tabular}

* Inoculation of $0.1 \mathrm{~mL}$ of amebae $\left(1.0\right.$ to $\left.2.5 \times 10^{6}\right)$ in hamsters which were sacrificed 6 days afetr inoculation. 
GOMES, M.A.; COSTA, A.O.; TAFURI, W.L. \& SILVA, E.F. - An attempt at reversibility and increase of the virulence of axenic strains of Entamoeba

histolytica. Rev. Inst. Med. (rop. S. Paulo, 35 (6):503-508, 1993.

média virulência (ICB-462). Todas as tentativas de tornar virulentas, restabelecer ou aumentar a virulência das cepas axênicas de E. histolytica utilizadas fracassaram.

\section{ACKNOWLEDGEMENTS}

We are indebted with the Development Center of Nuclear Technology by irradiation service and to Marcia A. Silva for able technical assistance. We are grateful to Dr. Paul Williams for correcting the manuscript. This work was supported by CNPq, FINEP and FAPEMIG.

\section{REFERENCES}

1. BOHL, K.C.; MUKHIERJEE, R.M.; BANERJEE, M. \& MAITRA, T.K. - Enhancement of virulence of Entamoeba histolytica by in vitro liver treatment. Ann. trop. Med. Parasit., 85: 341-344, 1991.

2. BOS, H.J. \& VAN DE GRIEND, R.J. - Virulence and toxicity of axenic Entamoeba histolytica. Nature, 265: 341-343, 1977

3. BOS, H.J. - Entamoeba histolytica: cytopathogenicity of intact amoebae and cell free extracts: isolation and characterization of an intracelular toxin. Exp. Parasit., 47: 369-377, 1979.

4. BRACILA, R. \& MIRELMAN, D. - Adherence and ingestion of Escherichia coli serotype 055 by trophozoites of Entamoeba histolytica. Infect. Immun., 40: 882-887, 1983.

5. BRACHA, R. \& MIRELMAN, D. - Virulence of Entamaeba hislolytica trophozoites: effects of bacleria, microaerobic conditions and metronidazole. J. exp. Med., 160: 353-368, 1984.

6. BRUMPT, E. - Étude sommaire de 1' "Entamoeba dispar" n. sp. A nibe à quistes quadrinuclées, parasite de l'lomme. Bull. Acad. Méd.(Paris), 94: 943-952, 1925.

7. CHAIA, G.; SILVA, E.F.; VILELA, C.C. \& CHIARI, L. - Isolation and maintenance of a strain of Entamoeba histolytica - Shaudinn, 1903 and possibility of its utilization in screening of drugs. Rev. Inst. Med. trop. S. Paulo, 19: 195-201, 1978.

8. DAS, S.R. \& GHOSHAL, S. - Restoration of virulence to rat of axenically grown by cholesterol and hamster liver passage. Ann. trop. Med. Parasit., 70: 439-443, 1976.

9. DE LA TORRE, M.; DE LA HOZ, R.; LANDE, L. \& SEPULVEDA, B. - Cultivos axênicos de Entamoeba histolytica. Arch. Invest. med. (Méx.), 2: 165-169, 1978.

10. DIAMOND, L. - Techniques of axenic cultivation of Entamoeba histolytica Shaudinn, 1903 and Entamoeba histolytica like amebae. J. Protozool., 54: 1047-1056, 1968.

11. DIAMOND, L.; PHLLLIPS, B.P. \& BARTGIS, I.L. - A comparison of the virulence of nine strains of axenically cultivated Entamoeba histolytica in hamster liver. Arch. Invest. med. (Méx.), 5: 423-426, 1974.

12. DIAMOND, L.; HARLOW, D.R. \& CUNNICK, C.C. - A new medium for the axenic cultivation of Entamoeba histolytica and other Entamoeba. Trans. roy. Soc. trop. Med. IIyg., 72: 431-432, 1978.

13. GRAHAM CLARK, C.; CUNNICK, C.C. \& DLAMOND, L. - Enamoeba histolytica: is conversion of "Nonpathogenic" amebae to the "Pathogenic" form a real phenomenon? Exp.Parasit., 74: 307314, 1992.
14. LUSHBAUGH, W.B.; KAIRALLA, A.; LOADHOLT, C.B. \& PITTMAN, P.E. - Effect of hamster liver passage on the virulence of axenically cultivated Entamoeba histolytica. Amer. J. trop. Med. Hyg., 27: 248-254, 1978.

15. MARTINEZ-PALOMO, A. - Parasite factors of virulence, in the biology of Eniamoeba histolytica. Baffins' Lane, John Wiley \& Sons, Research Studies Press, 1982. p.95-117.

16. MATTERN, C.F.T.; KEISTER, D.B. \& NATOVITZ, P.C. - Virulence of Entamoeba hitolytica upon continuous axenic cultivation. Arch. Invest. med.(Méx.), 13: 185-190, 1982.

17. MIRELMAN, D.; BRACHA, R.; WEXLER, A. \& CHAYEN, A. Changes in isoenzyme patterns of a cloned culture of nonpathogenic Entamoeba histolytica during axenization. Infect. Immun., 54: 827-832, 1986

18. NEAL, R.A. \& VINCENT, P. - I. Strain variation in Entamoeba histolyfica. II. The effect of serial liver passage on the virulence. Parasitology, 46: 173-182, 1956

19. OROZCO, E.; MARTINEZ-PALOMO, A. \& LOPEZ-REVILA, R. Un modelo "in vitro" para el estudio cuantitativo de la virulencia de Enamoeba histolytica. Arch.Invest.med. (Méx.), 9: 257-260, 1978.

20. OROZCO, E.; GUARNEROS, G.; MARTINEZ-PALOMO, A. \& SANCILEZ, T. - Entamoeba histolytica. Phagocytosis as a vinulence factor. J. exp. Med., 158: 1511-1521, 1983.

21. PIILLIPS, B.P. \& GORSTEIN, F. - Effects of different species of bacteria on the pathology of enteric amebiasis in monocontaminated Guinea pig. Amer. J. trop. Med. Hyg., 15: 863-868, 1966.

22. PLILLIPS, B.P. - Entamoeba histolytica: concurrent irreversible loss of infectivity/pathogenicity and encystment potential after prolonged maintenance in axenic culture "in vitro". Exp. Parasit., 34: 163$167,1973$.

23. RAVDIN, J.L. \& GUERRANT, R.L. - Role of adherence in cytophatogenic mechanisms of Entamoeba histolytica. Study with mammalian tissue cultures and human red blood cells. J. clin. Invest., 68 1305-1313, 1981.

24. Silva, E.F; CARVAllo, M.G. \& BRANDÃO, M.G.L. Monoaxenização e cultivo de amostras de Entamoeba histolytica isoladas no Brasil de pacientes sintomáticos e assintomáticos. In: CONGRESSO BRASILEIRO DE PARASITOLOGIA, 6, Belo Horizonte, 1981. Resumos. p. 18

25. SILVA, E.F. - Virulence of Entamoeba histolytica. Performance of various samples in axenic culture inoculated into hamsters at different ages. Mem. Inst. Oswaldo Cruz, 82 (suppl. 1): 29, 1987. (Abstract PZ-30).

26. SILVA, E.F.;TAFURI, W.L.; PENA, G.P. \& PIRES,E.M. - Evolution of hepatic lesion experimentally induced the inoculation of axenic strains of Enamoeba histolytica into the liver of hamsters (Mesocricetus auratus). Mem. Inst. Oswaldo Cruz, 84 (suppl.): 163, 1989.

27. TRISSL, D.; MARTINEZ-PALOMO, A.; DE LA TORRE, M.; DE LA HOZ, R. \& PEREZ SUAREZ, E. - Surface properties of Entamoeba histolytica: increased rates of human erythrocyte phagocytosis in pathogenic strains. J. exp. Med., 148: 1137-1145, 1978.

28. WITTNER, M. \& ROSEMBAUN, R.M. - Role of bacteria in modifying virulence of Entamoeba histolytica: studies of amebae from axenic cultures. Amer. J. trop. Med. Hyg., 19: 761-775, 1970.

Recebido para publicą̧ão em 15/02/1993 Aceito para publicação em 23/08/1993. 